\title{
Research on the Effectiveness of Economic Structural Adjustment in Tianjin
}

\author{
Xuelin Zheng \\ School of Economics and Management \\ Inner Mongolia University \\ IMU \\ Hohhot, China \\ Yunling Luo \\ School of Science \\ Tianjin University of Commerce \\ Tianjin, China
}

\author{
Zhanxin $\mathrm{Ma}^{*}$ \\ School of Economics and Management \\ Inner Mongolia University \\ IMU \\ Hohhot, China \\ *Corresponding author \\ Jianye An \\ School of Science \\ Tianjin University of Commerce \\ Tianjin, China
}

\begin{abstract}
The economic growth rate of China has gradually present a downward trend after 30 years sustained high-speed growth. Therefore, the improvement of economic efficiency and the optimization of industrial structure is a necessary requirement for sustainable development of China's economy. This paper not only analyzes the shortcomings of traditional DEA method applied in the industrial structure adjustment, but also proposes a new approach and model. Finally, we analyze the effectiveness of economic growth and give some information on industrial structure adjustment in Tianjin in the past 27 years.
\end{abstract}

Keywords-efficiency of economic growth; industrial structure adjustment; multiple objective decision making; data envelopment analysis

\section{INTRODUCTION}

Industrial structure is an important part of the economic structure, it refers the proportional relationship among industries and sectors. Recently, the power of central regulation is weakening and the power of market regulation is increasing, as a result, industrial structure adjustment is playing a more and more important role on economic growth. China's economy growth rate has gradually slowed down after 30 years' sustained high-speed growth. To achieve the sustainable development of China's economy, we need to improve the efficiency of economic growth, as well as achieve the adjustment and optimization of industrial structure.

Data Envelopment Analysis (DEA) is a kind of non-parametric statistics method, which is used by America operational research experts Charnes, Cooper et al in 1978. They took linear programming model to evaluate the relative efficiency of decision making units(DMU), which has the same type of multiple inputs and outputs.Chinese scholars have also made various explore in estimating economic efficiency and optimizing industrial structure by DEA. For instance, Xu Xiaoying(2010) used Malmquist index method, taking data from 13 prefecture-level cities in Hubei Province during 2000 2008 to analyze the input-output efficiency of the province by software DEAP2.1, Guo Jian mei, Wang Li(2011) collected six inputs and four outputs to evaluate the relative efficiency of industrial structure optimization in Dalian during 2000 2009 based on the input-oriented model $\mathrm{C}^{2} \mathrm{R}$, Cao Jianbiao et al(2009) also analyzed the industrial structure benefit of Shanshan County in Xinjiang Province based on the model $\mathrm{C}^{2} \mathrm{R}$.

All the methods above have certain practicality and effectiveness in solving their respective problems, but there are still two main disadvantages: (1) Generally, industrial structure adjustment is not the same proportion growth among three industries, (2) Each industrial output value is used as output indicators, the traditional DEA method requires these indicators the bigger the better, while, in fact, the adjustment of industrial structure needs to build a kind of rational structure.

\section{ECOMOMIC EFFICIENCY AND INDUSTRIAL STRUCTURE AdJUSTMENT BASED ON DEA MODELS}

To improve the efficiency of economic development through economic restructuring is a hot issue in economic study. Currently, DEA method has been widely applied in evaluating economic efficiency. Both domestic and foreign scholars have taken lots of useful research on economic structure adjustment by DEA, but there still remain some problems need to be solved. The following example is a common model to analysis economic structural adjustment.

Assuming there is an economic system, and the input indicators include the number of labor (L), the gross capital formation $(\mathrm{C})$ and the total energy consumption( $\mathrm{R})$, the output indicators are the gross domestic product $(\mathrm{Y})$. In order to reflect the economic system structure, we take the outputs value of three industries (first, second and tertiary industry) as another three outputs indicators $\left(Y^{a}, Y^{b}, Y^{c}\right)$. Dealing with this kind of problem, the traditional DEA method is as follow: 


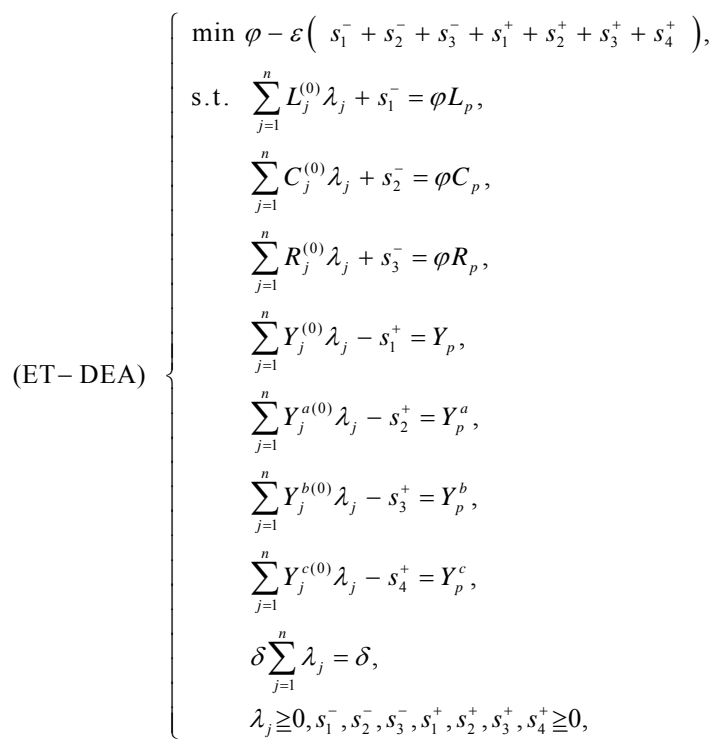

suppose $\varepsilon$ as Non-ARCHIMEDEAN infinitesimal.

Obviously, in the indicators that reflect economic efficiency, decision makers hope the inputs the smaller the better and the outputs the bigger the better. While among the indicators that reflect economic structure, they are not necessarily the bigger the better or the smaller the better, but to achieve a kind of rational structure. Thus, we propose a new DEA model to evaluate economic structure adjustment. Compared to the traditional one, we only take GDP instead of three industries' output value as outputs indicator when analyzing economic growth and industrial structure adjustment. In fact, we take three industries' output value as structure restructuring indicators, which are reflected in the projection of DMU. And the specific method is as follow:

$$
(\text { ES- DEA })\left\{\begin{array}{cl}
\min & \varphi-\varepsilon\left(s_{1}^{-}+s_{2}^{-}+s_{3}^{-}+s_{1}^{+}\right), \\
\text {s.t. } & \sum_{j=1}^{n} L_{j}^{(0)} \lambda_{j}+s_{1}^{-}=\varphi L_{p}, \\
& \sum_{j=1}^{n} C_{j}^{(0)} \lambda_{j}+s_{2}^{-}=\varphi C_{p}, \\
& \sum_{j=1}^{n} R_{j}^{(0)} \lambda_{j}+s_{3}^{-}=\varphi R_{p}, \\
& \sum_{j=1}^{n} Y_{j}^{(0)} \lambda_{j}-s_{1}^{+}=Y_{p}, \\
& \delta \sum_{j=1}^{n} \lambda_{j}=\delta, \\
& \lambda_{j} \geqq 0, s_{1}^{-}, s_{2}^{-}, s_{3}^{-}, s_{1}^{+} \geqq 0,
\end{array}\right.
$$

suppose $\varepsilon$ as Non-ARCHIMEDEAN infinitesimal.

If the optimal solution of linear programming ES-DEA is $\lambda^{0}, s_{1}^{-0}, s_{2}^{-0}, s_{3}^{-0}, s_{1}^{+0}$

then $\left(\hat{L}_{p}, \hat{C}_{p}, \hat{R}_{p}\right)=\left(\theta L_{p}-s_{1}^{-0}, \theta C_{p}-s_{2}^{-0}, \theta R_{p}-s_{3}^{-0}\right), \hat{Y}_{p}=Y_{p}+s_{1}^{+0} \quad$ is the projection of DMU, and the corresponding restructuring information for each industrial outputs value is:

$$
\Delta Y_{p}^{a}=\sum_{j=1}^{n} Y_{j}^{a(0)} \lambda_{j}^{0}-Y_{p}^{a}, \Delta Y_{p}^{b}=\sum_{j=1}^{n} Y_{j}^{b(0)} \lambda_{j}^{0}-Y_{p}^{b}, \Delta Y_{p}^{c}=\sum_{j=1}^{n} Y_{j}^{c(0)} \lambda_{j}^{0}-Y_{p}^{c}
$$

\section{AN EMPIRICAL ANALYSIS ABOUT THE ECONOMIC GROWTH AND INDUSTRIAL RESTRUCTURING EFFECTIVNESS IN TianjIN BASED ON GENERALIZED DEA MEASUREENT METHODS}

\section{A. Indicators Select and Source of Data}

In order to reflect the usage of labor, capital and energy in Tianjin during economic construction, we choose the number of $\mathrm{L}$, $\mathrm{C}$ and $\mathrm{R}$ as analysis object. The data collected mainly from "China Statistical Yearbook" and Macro Economic Database. Original data includes the number of $\mathrm{L}$ at the end of year, the $\mathrm{C}$, the R, GDP, gross domestic product index (previous year $=100$ ). The data includes 30 provinces in China (except Tibet, for it's energy data is difficult to obtain) from 1986 to 2012. In order to make the data more comparable, we convert the data to constant price at 1985 .

In this paper, we take 30 provinces' macro economic data in 2012 as sample units, and take data from 1986 to 2012 in Tianjin as decision making units. Besides, we take the number of $\mathrm{L}$, the $\mathrm{C}$ and the R as inputs and take GDP as outputs, we also use the first, second and tertiary industries' outputs value to reflect the economic system structure.

\section{B. Comparative Analysis Based on Econometric Model ES-DEA and ET-DEA}

We take the number of $\mathrm{L}$, the $\mathrm{C}$ and the $\mathrm{R}$ as input variables, and take GDP as outputs variable. Then, we substitute the input variables and output variables into model(ES-DEA). Similarly, we take the number of $\mathrm{L}$, the $\mathrm{C}$ and the $\mathrm{R}$ as input variables, take GDP and three industries' outputs as output variables, and substituted them into model(ET-DEA).

At first, we use generalized DEA software to calculate and obtain the value of $\lambda$, slack variables and remaining variables of China's 30 provinces from 1986 to 2012, as well as the technological efficiency value in Tianjin over the past 27 years based on model $\mathrm{BC}^{2}$. Next, we calculate the projection of Tianjin's three industries' output value on production frontier. In 2012, the first, second and tertiary industries' output value in Tianjin is $Y_{p}^{a}=43.65, Y_{p}^{b}=275.70, Y_{p}^{c}=292.81$. (Unit: one trillion yuan).

Set up $\overline{Y_{p}^{a}} 、 \overline{Y_{p}^{b}} 、 \overline{Y_{p}^{c}}$ respectively represents the projection of the first, second and tertiary industries' output value in Tianjin, then

$$
\begin{gathered}
\overline{Y_{p}^{a}} \sum_{i=1}^{30} \lambda_{1} \cdot Y_{p i}^{a}=\lambda_{1} \cdot y_{p 1}^{a}+\lambda_{9} \cdot y_{p 9}^{a}+\lambda_{21} \cdot y_{p 21}^{a}+\lambda_{28} \cdot y_{p 28}^{a} \overline{Y_{p}^{b}} \sum_{i=1}^{30} \lambda_{i} \cdot Y_{p i}^{b} \\
=\lambda_{1} \cdot y_{p 1}^{b}+\lambda_{9} \cdot y_{p 9}^{b}+\lambda_{21} \cdot y_{p 21}^{b}+\lambda_{28} \cdot y_{p 28}^{b}
\end{gathered}
$$




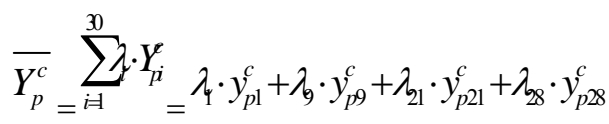

By substituting the 30 provinces' data in 2012 and the operation results by generalized DEA software into formula(1), we can get the projection of Tianjin's three industries' output value over the past 27 years.

These three industries' manual adjustment value:

$$
\Delta Y_{p}^{a}=\overline{Y_{p}^{a}} Y_{p}^{a}, \Delta Y_{p}^{b} \overline{Y_{p}^{b}} Y_{p}^{b}, \Delta Y_{p}^{c}=\overline{Y_{p}^{c}} Y_{-}^{c} .
$$

By substituting Tianjin's three industries' output value from 1986 to 2012 and the projection value into formula(2), we can get adjustment value for each industry. The results are shown in Figure I and Figure II.

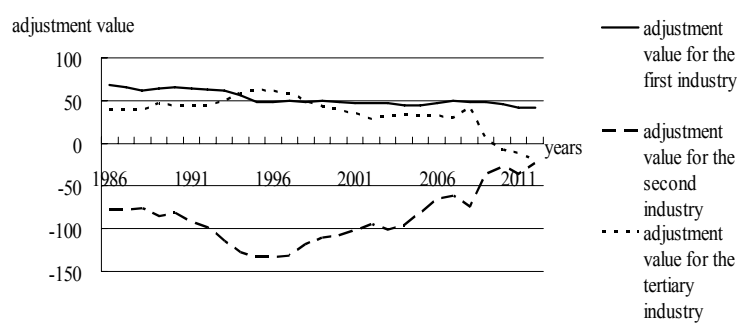

FIGURE I THREE INDUSTRIES' ADJUSTMENT VALUE FOR TECHNOLOGICAL EFFICIENCY BASED ON ES-DEA

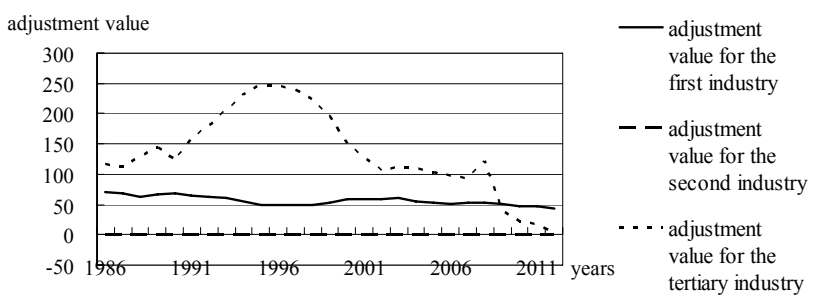

FIGURE II THREE INDUSTRIES' ADJUSTMENT VALUE FOR TECHNOLOGICAL EFFICIENCY BASED ON ET-DEA

Similarly, we can get Tianjin's three industries' adjustment value and comprehensive efficiency from 1986 to 2012. The results are shown in Figure III and Figure IV.

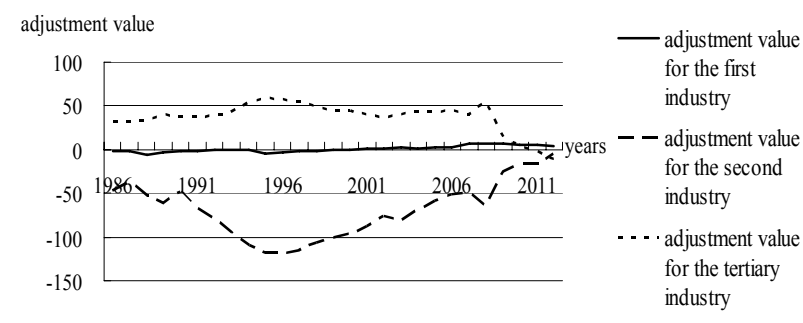

FIGURE III THREE INDUSTRIES' ADJUSTMENT VALUE FOR COMPREHENSIVE EFFICIENCY BASED ON ES-D

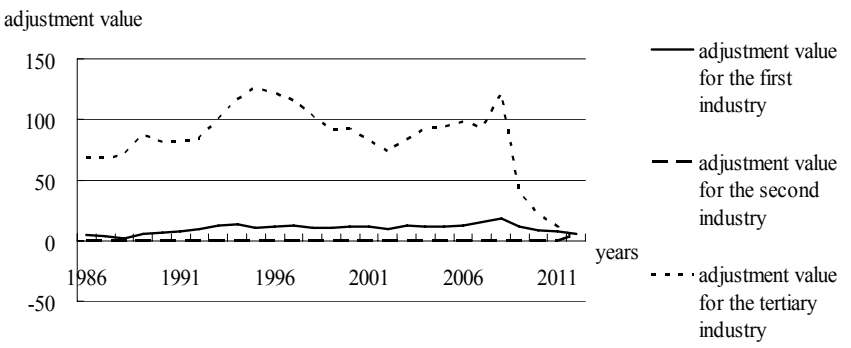

FIGURE IV HREE INDUSTRIES' ADJUSTMENT VALUE FOR COMPREHENSIVE EFFICIENCY BASED ON ET-DEA

According to the calculations based on model ES-DEA: the comprehensive efficiency value of Tianjin ranges from 0.7 to 0.9 , meanwhile the technological efficiency value ranges from 1.1 to 1.5 from 1986 to 1992 . It is shown that the comprehensive efficiency is lower than the best level in 2012, the technological efficiency is higher than the best level in 2012. In 1993 and 1994, the comprehensive efficiency and technological efficiency of Tianjin are both significantly higher than the best level in 2012, the comprehensive efficiency value is 1.5 and 1.8 , the technological efficiency value is 2.0 and 2.3. From 1995 to 2010 , the comprehensive efficiency value of Tianjin fluctuates between 0.9 to 1.0 , they are basically in line with the best level in 2012, at the same time, the technological efficiency value is still higher than the best level and maintains between 1.1 to 1.4. In 2011 and 2012, the comprehensive efficiency and technological efficiency of Tianjin are both lower than the best level in 2012, the comprehensive efficiency value is less than 0.7 , and the technological efficiency value is 0.8 .

According to the calculations based on model ET-DEA: the comprehensive efficiency value of Tianjin maintains between 1.2 to 1.5 , meanwhile the technological efficiency value basically maintains between 1.1 to 1.5 from 1986 to 1992 . It is shown that the comprehensive efficiency and technological efficiency are both higher than the best level in 2012. In 1993 and 1994, the comprehensive efficiency and technological efficiency of Tianjin are significantly higher than the best level in 2012, the comprehensive efficiency value is 2.9 and 3.4, the technological efficiency value is 3.5 and 3.9 from 1995 to 2010 (except for 1995 1997) the comprehensive efficiency and technological efficiency decrease year by year: after 2009, the comprehensive efficiency is lower than the best level in 2012, after 2011, technological efficiency is lower than the best level in 2012.

According to above two models, in 1993 1994, the comprehensive efficiency and technological efficiency achieve short-term peak, while in 2011 2012, they fall into the lowest.

By analyzing the calculations based on model ES-DEA, in order to improve the comprehensive efficiency of Tianjin, from 1986 to 1999 , we should reduce investment in the first and second industry, as well as develop the tertiary industry. From 2000 to 2010, due to the second industry has taken up overmuch production factors, we should moderately increase support for the first industry, and develop the tertiary industry continually. In 2011 2012, excessive investment makes production factors cannot be effectively utilized and results in a waste of resources, thus, we should reduce investment into the second and tertiary 
industries to improve economic efficiency. In order to improve the technological efficiency of Tianjin, from 1986 to 2012, we should increase investment in the first industry continually. The second industrial has no effectively due to excessive investment and results in a low productivity, thus, we should reduce the investment into the second industry. Before 2009 (include 2009), we should develop the tertiary industry, after 2009, we should reduce the investment in it.

By analyzing the calculations based on ET-DEA model, in order to improve the comprehensive efficiency of Tianjin, we should increase investment in the first industry modestly year by year. The second industry has reached the maximum production efficiency and need not to be adjusted. From 1986 to 2008 , we should develop the tertiary industry and increase the investment in labor, financial and energy. After 2009, the development of the third industrial has begun to take shape, so we can properly reduce the increase of production inputs. In order to improve the technological efficiency of Tianjin, from 1986 to 2012, we should continually increase investment in the first industry, and the second industry could maintain the original input level. Before 2009 (include 2009), we should develop the tertiary industry, after 2009, we need to appropriately weaken the support for the tertiary industry.

As can be seen from all the above, according to model ET-DEA, the adjustment value of three industries are all greater than or equal to zero, that is, the outputs are still need to be improved. The adjustment value from model ES-DEA are positive or negative, it reflects that through rational allocation and effective use of the production among various industries can achieve optimal comprehensive productivity.

\section{CONCLUSION}

Currently, the study of industrial structure adjustment by DEA is still needs a further research. In our empirical analysis, the DEA model of economic growth and industrial structure adjustment effectiveness reflects the practicability and superiority. In addition, the innovation of the model is, it does not take three industries' production value as outputs, but only with GDP. And then, calculating the economic efficiency of the target province and the projection of three industries' production value on production frontier. At last, according to certain proportion, we calculate the adjustment value of each industry to achieve the economic growth and the production efficiency. This method has great significance in speeding up the adjustment and upgrade of industrial structure in China.

\section{ACKNOWLEDGEMENTS}

This work is financially supported by National Natural Science Foundation of China (71271084, 71261017, 70961005) and Tianjin Education Commission of Social Sciences major projects (2012ZD35).

\section{REFERENCES}

[1] Charnes A, Cooper W W. and Rhodes E. Measuring the efficiency of decision making unit $[\mathrm{J}]$. European Journal of Operational Research, 1978, 2: 429-444.
[2] Banker R D, Charnes A and Cooper W W. Some models for estimating technological and scale inefficiencies in data envelopment analysis[J]. Management Science, 1984, 9: 1078-1092.

[3] Färe R. and Grosskopf S. A non-parametric cost approach to scale efficiency [J]. The Scandinavian Journal of Economics, 1985, 87: 594-604.

[4] Seiford L M and Thrall R M. Recent development in DEA, the mathematical programming approach to frontier analysis [J]. Journal of Econometric, 1990, 46:7-38.

[5] Ma Z. Data Envelopment Analysis model and method. Science Press, Beijing 2010.

[6] XU Xiao-ying. Efficiency analysis of regional economic growth in Hubei based on DEA-Malmquist method [J]. Statistics and Decision, 2010, (22): 88-91.

[7] GUO Jian-mei, WANG Li. Based on DEA of Dalian Industrial Structure Optimization Evaluation [J]. Resource Development\&Market, 2011, 27(04) 308-310.

[8] CAO Jian-Biao, ZHANG Xiao-Lei, DUHong-Ru, LI Xue-Mei. Efficiency evaluation of the urban industrial structure based on DEA model: A case of Shanshan County [J]. Journal of the Graduate School of the Chinese Academy of Sciences, 2009, 26(6): 759-764.

[9] National Bureau of Statistics of the People's Republic of China. China Statistical Yearbook (1986-2012) [M]. Beijing: China Statistics Press. 